\title{
A NECESSIDADE DO RETORNO À OBRA NO CASO BRASILEIRO
}

Renata Gomes Cardoso ${ }^{1}$

Estamos todos fadados a ser também críticos de arte, para que possamos chegar a historiadores. Rodrigo Naves, A forma difícil

As questões aqui levantadas tiveram origem na reflexão sobre metodologias em história da arte e no desafio de se estabelecer e relacionar esse conjunto na abordagem de pinturas da artista Anita Malfatti, que possui uma posição muito peculiar no interior da arte moderna brasileira. A leitura dessas fontes teórico-metodológicas coincidiu com a observação de um número crescente de discussões em nosso meio em torno dessa problemática. O desafio metodológico na abordagem da arte brasileira é ainda uma questão complexa, levando-se em conta as particularidades de nosso universo artístico e, em conseqüência, dos estudos que o cercam. A preocupação com questões teóricometodológicas nesse sentido, não só em relação a trabalhos específicos da área, como também em relação à própria estrutura de cursos relacionados à história da arte no país, vem sendo aos poucos discutida em congressos e encontros da área, como os Colóquios do CBHA e recentemente com o Encontro da Unicamp. Em princípio, a dificuldade relacionada com os métodos e as teorias de abordagem na disciplina surge quando nos vemos diante de um objeto artístico que continua exigindo da disciplina, por razões epistemológicas, uma outra ou nova abordagem.

Em algumas discussões levantadas nesses congressos e encontros, é possível identificar duas questões principais nesse contexto: em primeiro lugar uma preocupação crescente com a necessidade de um retorno ao objeto, para dele extrair os elementos que permitirão as interpretações e relações possíveis com sua cultura visual. Em segundo lugar, a preocupação com uma necessidade de interdisciplinaridade nos estudos da história da arte, que surge principalmente em conseqüência dos novos desafios propostos pela arte contemporânea, o que vem refletir ainda a inserção da disciplina no campo das ciências humanas. Para o primeiro caso, não é preciso ir muito longe, procurando, por exemplo, nas teorias da arte internacionais ${ }^{2}$ a base para essa reflexão. É possível identificar essa questão nas preocupações dos pesquisadores atuais da história da arte brasileira. O retorno ao objeto, como propõe Jorge Coli ${ }^{3}$, é o que possibilita a reflexão sobre a "cultura do olhar", que envolve uma interação específica entre sujeito e objeto, sendo essa capaz, através de um olhar que interroga, rever conceitos classificatórios e evitar "categorias que, em última análise, sempre são determinadas pelas escolhas do momento - estéticas, culturais, ideológicas", e muitas vezes carregam pontos de vistas determinantes ao longo de nossa tradição histórico/artística, mas que são, entretanto, insuficientes para uma compreensão mais ampla do fenômeno estudado. A concentração na obra transportaria dessa forma, a atenção que é dada ao geral - no caso o contexto e, segundo Coli, os "pressupostos

\footnotetext{
${ }^{1}$ Mestre em História da Arte pelo IFCH/UNICAMP.

2 As teorias de análise estrutural. Ver, por exemplo, WOOD, Christopher. The Vienna School Reader: Politics and Art Historical Method in the 1930. NY: Zone Books, 2000; BARASCH, Mosche. Theories of Art 3: From Impressionism to Kandinsky. NY and London: Routledge, 2000.

3 COLI, Jorge. "Questões sobre a arte brasileira do séc. XIX". In, XXII Colóquio Brasileiro de História da Arte, Anais. CBHA, 2002; COLI, Jorge. "Pedro Américo, Vitor Meireles, entre o passado e o presente". In, Revisão Historiográfica: o estado da questão. Atas do I EHA-IFCH/UNICAMP. Campinas, IFCH, 2005, p. 106115.
} 
culturais" ${ }^{4}$, normalmente impostos às obras - para o particular, sendo esses os desafios que o próprio objeto propõe, e que gera, a partir da reflexão criada com esse contato, as devidas relações com as correntes culturais do contexto ao qual ele pertence. Tal problemática colocada pelo historiador, apesar de se centrar nos estudos da arte do século XIX, pode ser pensada e ampliada para outros períodos das artes brasileiras.

Em seu ensaio sobre a "forma difícil" 5 , por exemplo, Rodrigo Naves pontua essa questão de forma semelhante, mas voltado dessa vez para a situação da arte moderna brasileira, reconhecendo nela características tão particulares em relação à arte em geral, (o que de fato ocorre também em outros períodos) que tornam inviáveis, por exemplo, a "sobreposição de esquemas teóricos" mais complexos aos estudos, sendo, portanto, também contraditórias algumas periodizações e classificações, relacionadas a uma produção que até certo ponto não apresenta "um diálogo real entre si" para que sejam entendidas em "uma dinâmica efetiva" ". A conseqüência imediata de tais particularidades - hoje bem conhecidas por qualquer estudioso de qualquer período da arte brasileira - seria, ainda segundo Naves, uma exigência do próprio objeto a um contato mais "estreito e continuado" com a obra, para além dos métodos objetivos de interpretação. A finalização de Naves é, no mínimo, instigante: "estamos todos meio fadados a ser também críticos de arte, para que possamos chegar a historiadores" 7 .

Cada um a seu modo, e com um grupo de obras de períodos diferentes, demonstra certa insuficiência na aplicação de esquemas teóricos específicos em um campo que ainda denuncia a urgência e a necessidade de uma maior proximidade e contato com as obras. As preocupações dos dois historiadores são muito válidas, se observarmos que, ao longo dos estudos sobre a arte brasileira, principalmente se pensarmos naqueles relacionados com a arte moderna, há uma abundância de fontes voltadas para, por exemplo, aspectos biográficos ou aspectos que inserem o artista nesses "pressupostos culturais" do contexto, inevitavelmente passados ao longo dessa historiografia, e que podem carregar, seja por questões ideológicas, conceituais ou de filiações, "generalizações perigosas".

Como atentou a historiadora Yacy-Ara Froner, em seu texto para o I EHA, "compreender o contexto histórico de onde parte o objeto artístico e o repertório imagético, tecnológico, conceitual e fenomênico que impregna o processo criativo (...) significa orientar-se de maneira diversa daquela pesquisa que submete apenas à biografia do autor a conseqüência imediata de sua proposição" " Não estamos afirmando que o recurso a essas fontes não seja importante, muito ao contrário, elas trazem, muitas vezes, informações valiosas sobre artistas, períodos e contextos culturais, e será ainda sem dúvida a partir de tais informações que formularemos, por exemplo, as questões para investigação e para a atualização crescente dos estudos em arte. Entretanto, como ainda salientou Froner, "situar a obra não é simplesmente inseri-la em um momento cronológico específico; antes, é perceber de que modo e em que medida ela compartilha o conjunto das idéias vigentes, sendo ao mesmo tempo testemunho e promotora de uma percepção, uma maneira de ver e se relacionar com o real, estabelecendo um diálogo de mão dupla com o

\footnotetext{
${ }^{4} \mathrm{O}$ termo é do historiador citado.

${ }^{5}$ NAVES, Rodrigo. A forma difícil - ensaios sobre arte brasileira. São Paulo: Ática, 2001, p. 9-38.

6 Segundo ainda Naves tal dinâmica só poderá ser observada "a partir do debate entre concretos e neoconcretos, na década de 50".

7 Idem, ibdem, p. 12.

8 FRONER, Yacy-Ara. "Historiografia da arte no Brasil: Por um regime de oposições". In. Revisão bistoriográfica - o estado da questão. Campinas: IFCH, 2005, p. 236.
} 
seu próprio tempo: alimentando-se dele e para ele fornecendo o alimento" " . Os estudos que de certa forma partem de uma compreensão da obra para o contexto geral, fazendo assim o caminho inverso do que é normalmente encontrado em estudos gerais, são mais raros, mas seu número vem aumentando atualmente.

Esse foco nas particularidades do meio é visível em outras argumentações, e tem trazido uma conseqüência absolutamente positiva para o nosso contexto, pois promove assim uma séria revisão das fontes, e em conseqüência, do contexto histórico onde essas se inserem, aumentando o número de publicações, cujo conteúdo, como colocou a pesquisadora Almerinda da Silva Lopes no CBHA de 2002, "extrapola ou subverte hierarquias e conceitos, valores e critérios de gosto cristalizados", o que torna possível, "rever as intenções, os gestos e as ações dos nossos artistas sem atrelá-los, necessariamente, à camisa de força da arte internacional, ou como aproximações genéricas e abstratas, mas como denominadores comuns para a estruturação de uma teoria da arte menos vaga e hesitante do que as de um passado não tão remoto" " ${ }^{10}$. A pesquisadora vê nesse aumento de publicações a possibilidade de "vínculos mais precisos e coerentes" com os contextos onde obra e criador se inserem, o que abre "um novo espaço de compreensão do trabalho crítico da cultura".

Tais colocações são interessantes quando pensadas, por exemplo, em relação à questão específica de Anita Malfatti no contexto do modernismo brasileiro. Vemos na grande maioria dos estudos sobre esse período e nos quais a artista é sempre citada, uma tendência sempre forte de se vincular os acontecimentos do entorno de 1917 para o entendimento de todo o conjunto de sua obra, que receberá então, a partir desse contexto e da crítica contemporânea a ela, algumas classificações da arte moderna, como o expressionismo, dentre outros, num primeiro momento; e de arte acadêmica ou ainda impressionismo, em um segundo momento. As determinações do meio, especificamente do início do século XX, com os artigos em disputa em torno da arte moderna e de uma pintura naturalista, se refletem ainda hoje na maioria das abordagens sobre a obra da artista, mesmo já sendo de certa forma claro nos estudos sobre o modernismo que os termos utilizados por seus contemporâneos, seja de um lado, seja de outro, eram termos dificilmente compreendidos em sua totalidade por aqueles que os utilizavam. Os termos continuam por vezes sendo repetidos sem que se interrogue a obra, para as possibilidades de vinculação a eles. Surge assim uma necessidade de rever a obra com certo distanciamento das determinações que o meio aos poucos impôs, para que se possa retornar ao meio desvinculadas dos pré-conceitos pelos quais as obras foram sempre vistas, em uma tentativa de avaliar aquele contexto por novas perspectivas.

Não seria difícil também ampliar tal discussão para outros artistas que fazem parte da arte moderna brasileira, já que a crítica modernista, em seu engajamento por uma "renovação" cultural, lançava julgamentos que ora afastava, ora aproximava os artistas de certa relevância e importância no meio, como forma de afirmação de seus pressupostos. Será dessa forma que conjuntos de obras de vários artistas do período ficarão marcados no movimento em determinado momento, e outro conjunto será relegado ao esquecimento, porque o artista ora era modernista "por excelência", ora fugia daqueles pressupostos de reafirmação. Para citar novamente Coli, "vale mais, portanto, colocar de lado as noções e

\footnotetext{
${ }^{9}$ Idem.

10 LOPES, Almerinda da Silva. "Identidade ou identidades artísticas brasileiras?". In. XXII Colóquio Brasileiro de História da Arte. CBHA, 2002.
} 
interrogar as obras", distante de "parâmetros seguros e confortáveis, mas profundamente limitados" $" 11$.

O entendimento das particularidades do meio e da necessidade de retorno à obra, não nos isenta do compromisso com as preceptivas específicas da história da arte, pois será a partir daí que poderemos traçar, como já é possível perceber em certas atitudes dos centros de pesquisa da área, uma formação sistematizada da disciplina, que implica no estudo e na revisão dos estudos em torno das teorias e metodologias ao longo da história da arte. Tal reflexão virá contribuir para exercitar nossas capacidades de entendimento em geral do objeto que propomos estudar e amplia as questões em torno das especificidades desse objeto diante de um cenário geral das artes. As teorias serão então válidas para se propor um conjunto estruturado de idéias quando esse conhecimento específico estiver inserido num todo que reflita a relação sujeito/objeto, e não utilizadas à revelia, causando mais estranhamento nas análises, do que um entendimento propriamente dito do objeto na sua complexidade e seu entorno.

${ }^{11}$ COLI, Jorge. Op. Cit, p. 106-115. 